\title{
La metodología de la abducción en el caso del descubrimiento del megaterio*
}

\author{
Antonio Duarte Calvo
}

Received: 29/03/2016

Final Version: 10/06/2016

BIBLID 0495-4548(2017)32:2p.191-209

DOI: $10.1387 /$ theoria.16162

RESUMEN: En este artículo se analiza el caso del descubrimiento del megaterio (el primer animal extinto reconstruido) desde una perspectiva abductiva, prestando atención al proceso de generación y selección de hipótesis de algunos de los actores involucrados en este singular acontecimiento. El análisis muestra la importancia de ciertos puntos metodológicos relacionados con la práctica y el rigor científico para proponer hipótesis plausibles.

Palabras clave: abducción, ciencias naturales, historia de la ciencia, megaterio, metodología de la abducción.

ABSTRACT: In this article, I analyzed the case of the discovery of the megatherium (the first extinct animal reconstructed) from an abductive perspective, paying attention to the process of hypothesis generation and selection of some of the agents involved in this unique event. The analysis shows the importance of certain methodological issues related to scientific rigor in order to propose plausible hypotheses.

Keywords: abduction, abductive methodology, history of science, megatherium, natural science.

\section{Introducción}

En este artículo trataremos el proceso de descubrimiento siguiendo la teoría de la abducción de C. S. Peirce (ver por ejemplo, Fann 1970; Aliseda 2006; Niño 2007). Podemos resumir la abducción como una clase razonamiento que introduce una nueva idea, siendo esta idea tentativa y relativa a un contexto dado. A través de la abducción, cuando nos encontramos ante lo que podemos considerar unos hechos sorprendentes, generamos hipótesis plausibles que pueden ser evaluadas siguiendo los tres estadios de la investigación peirceanos que emergen a raíz de los tres tipos distintos de inferencia (abducción, deducción e inducción). De esta manera, la abducción es el proceso de generar y evaluar hipótesis de acuerdo con los tres estadios de la investigación (Peirce, CP 7.202-7.207, 1901). Aunque ciertos puntos de este proceso puedan parecer algo instintivos (véase el insight ${ }^{1}$; Peirce, CP 5.181, 1903), el

* Agradezco a Susana Gómez el haberme dado a conocer el estupendo trabajo de Juan Pimentel y a Javier Vilanova la detallada lectura de la versión previa de este trabajo. Asimismo, agradezco a los dos revisores anónimos de Theoria sus comentarios que han contribuido a la mejora de este artículo.

1 La traducción más directa del insight peirceano podría ser «destello». El «destello» con el que se ilumina una nueva idea que, quizás, a los pocos segundos devendrá en hipótesis. Sin embargo, este destello surge mediante una actividad racional y crítica. En Duarte (2015) lo denominé instante del instinto con el fin de enfatizar que, a lo largo del proceso abductivo (proceso imaginativo, pero a la vez crítico y racional) tan solo existe ese instante en el que reordenamos las piezas de manera poco consciente, instintiva. 
proceso abductivo requiere de un ejercicio de logica docens ${ }^{2}$, esto es una inmersión voluntaria y activa en el contexto que nos guíe hacia la resolución del enigma.

Aunque no hay reglas operativas estrictas para el razonamiento abductivo, esta forma de hipotetizar de manera voluntaria apunta hacia la observación de una metodología (en sentido laxo) para generar lo que podríamos considerar «buenas» abducciones. Estas «buenas» abducciones no se identifican con abducciones correctas, verdaderas o infalibles, sino con aquellas que se enuncian críticamente, aquellas en las que podemos argumentar nuestra elección de manera plausible ya que explican, de alguna manera, los datos recogidos hasta ese punto de la investigación. Los ensayos recogidos en el volumen de Eco y Sebeok (1988) abordan la metodología de los famosos detectives de la literatura que les guían a realizar buenas abducciones. Hintikka $(1998 ; 2007)$ distingue entre reglas definitorias, aquellas permitidas a la hora de hacer inferencias (las reglas de transformación, que existen para deducción e inducción) y reglas estratégicas, las propias de la abducción, aquellas que dependen del contexto y que se basan en hacer las preguntas adecuadas. Por otro lado, Walton (2004) propone ciertas fases por las que debe pasar el razonamiento abductivo para poder ser críticamente evaluado. Paavola (2004) y Anderson (2005) señalan ciertos puntos metodológicos útiles a la hora de abducir. En Duarte (2015) he tratado de seguir la estela de estos autores proponiendo los métodos de evaluación argumentativos para el estudio de la abducción.

En definitiva, se trata de poder someter a crítica las abducciones, tanto las nuestras como aquellas generadas por otras personas. Por lo tanto, es conveniente observar y analizar ciertos puntos metodológicos o reglas estratégicas (siguiendo la nomenclatura de Hintikka) relacionados tanto con la práctica y el rigor científico como con la propia naturaleza falible y novedosa de las ideas surgidas a través de la abducción. En este artículo, destacaremos seis puntos que se discutirán en el análisis del caso propuesto:

(1) Sobreponerse a la odiosa rutina, es decir, superar los muros mentales, la fijeza funcional o Einstellung ${ }^{3}$ de nuestros razonamientos cotidianos guiados por nuestros hábitos.

(2) Prestar particular atención a lo que a priori pueden parecer pequeños detalles, aquellos ensombrecidos por evidencias o hechos en principio más llamativos pero que, en muchas ocasiones, son los que encaminan las investigaciones hacia una resolución satisfactoria.

(3) Actuar sin precipitación, no formular hipótesis que no expliquen los datos sorprendentes por el solo hecho de querer avanzar.

2 En este artículo se entenderá el concepto de logica docens inmerso en la filosofía pragmatista peirceana (ver, por ejemplo, Peirce CP 2.188-2.190, 1902; CP 5.108, 1903; CP 5.130, 1903; Pietarinen 2005, 368; Chiasson 2001; Niño 2007, 142). Por tanto, los razonamientos deliberados y críticos se mueven en el dominio de la logica docens, en contraposición a los razonamientos cotidianos guiados por nuestros hábitos donde es la logica utens la intermediaria. En este sentido, este concepto es más amplio que aquel originario procedente de los filósofos escolásticos, para quienes la logica docens era aquella adquirida a través del estudio de la lógica. En definitiva, en este artículo aludiremos a la logica docens cuando el problema a resolver sea abordado con una mirada crítica.

3 Este término era usado por psicólogos como Duncker, Luchins o Adams: Einstellung (acostumbramiento) sería «un estado mecanizado de la mente, una actitud ciega ante los problemas; no se mira el problema por sus propios méritos sino que se acompaña por la aplicación mecánica de un método ya utilizado» (Mayer 1986, 76). 
(4) Formular hipótesis alternativas que sean susceptibles de explicar los hechos hasta ese punto de la investigación y tratar de verificarlas o falsarlas.

Conectando con estos dos últimos puntos y con el caso particular que describiremos en este artículo, podemos hablar brevemente del Principio de Economía en la Investigación de Peirce (Peirce, CP 7.139-157, 1879) sobre el que volvió frecuentemente en sus escritos posteriores y que aplicó también al proceso de selección de hipótesis:

$[\mathrm{T}]$ res consideraciones deben determinar nuestra elección de hipótesis. En primer lugar, tiene que poder ser sometida a comprobación experimental [...] En segundo lugar, la hipótesis debe ser tal que explique los hechos sorprendentes que tenemos ante nosotros [...] En tercer lugar, casi una consideración tan necesaria como las otras dos que he mencionado, y en vista del hecho de que la verdadera hipótesis es tan solo una de entre las innumerables posibles hipótesis falsas, en vista, también, del enorme coste de la experimentación en dinero, tiempo, energía y pensamiento, es la consideración de economía. (Peirce, CP 7.220, 1901)

En estas consideraciones económicas lo importante es que, en igualdad de condiciones, hacen que la verificación o falsación de la hipótesis sea más sencilla. Como apunta Niño (2007, 376): «los criterios de la Economía de la Investigación de Peirce están enfocados a hacer que la investigación científica avance más rápidamente y no a que sea más explicativa, en cualquiera de sus variantes».

Continuando con los puntos anunciados previamente:

(5) Sumergirse en un diálogo razonado, pensando y presentando las ideas atendiendo a las normas del diálogo persuasivo (ver, por ejemplo, Walton 1992, 133) o de la discusión crítica (van Eemeren y Grootnedorst 1984) con el fin de alcanzar los objetivos del diálogo: al tratarse de abducción, generalmente, el objetivo del diálogo será la resolución de un enigma.

(6) Practicar ciertas virtudes epistémicas relacionadas con la naturaleza siempre falible de la abducción, especialmente, estar siempre en disposición de practicar la docta ignorancia (ver Debrock 1998) o ignorancia generosa (Montaigne 1998, 297), es decir, tener la honestidad suficiente para desechar hipótesis convenientemente falsadas o revisar nuestras hipótesis cuando se nos presentan evidencias que la contradicen, lo que sería equivalente a hacer las concesiones necesarias a la otra parte basadas en criterios racionales en un diálogo razonado.

En este artículo iremos analizando paso a paso un caso real de la historia de la ciencia, el descubrimiento del megaterio, desde esta perspectiva abductiva. Los puntos enumerados más arriba serán los que tendremos en mente para ir discutiendo las distintas hipótesis propuestas por diferentes actores de este episodio. El análisis revela los pasos, estrategias, actitudes y aptitudes involucrados en los procesos que implican hipótesis abductivas. En definitiva, de lo que se trata es de subrayar la importancia de un método o de unas normas que ayuden a encaminar una investigación.

A pesar de ser frecuentes los ejemplos de grandes descubrimientos científicos para ilustrar el razonamiento abductivo, es difícil encontrar trabajos donde estos sean diseccionados acorde con cierta metodología de la abducción. Son los trabajos de Rivadulla (2015), Paavola et al. (2006) y Paavola (2004) los que podemos destacar en este sentido. Una dificultad añadida a esta tarea reside en la dificultad de reconstruir la historia de un descubrimiento teniendo en cuenta los múltiples factores que pueden afectar al caso, por lo que son 
los relatos de los propios protagonistas o de los historiadores de la ciencia los más convenientes para el análisis que aquí se propone.

Este estudio se llevará a cabo a partir del trabajo del historiador de la ciencia Juan Pimentel sobre la reconstrucción del megaterio (Pimentel 2010). El caso del megaterio es de sumo interés porque se trata de un acontecimiento único y singular dentro de la historia de la anatomía animal. Fue el primer animal extinto reconstruido, animal colosal que se puede contemplar en un rincón casi oculto del Museo de Ciencias Naturales de Madrid. Una reconstrucción en donde la abducción será clave para interpretar el proceso, en un terreno en el que la imaginación, rigor científico y debate público constituirán una red explicativa imprescindible para entender este particular episodio.

Dividiremos este estudio en tres partes: primero, trataremos de describir ampliamente el caso (Sección 2); seguidamente abordaremos un análisis en donde iremos recogiendo los elementos que nos resultan más relevantes desde el foco abductivo (Sección 3); en la Sección 4 organizaremos estos elementos para su discusión; para finalizar, una breve conclusión será presentada en la Sección 5.

\section{El caso}

Contextualicemos, en la medida de lo posible, la historia del megaterio a partir del relato de Juan Pimentel:

En 1787, Francisco Aparicio, alcalde de la villa de Luján (Argentina), tiene noticias de que dentro de su jurisdicción están descubriendo unos huesos de enormes proporciones. Nuestro alcalde se pone en contacto con Manuel de Torres, un fraile dominico, amateur ilustrado (así lo califica Pimentel) con conocimientos de historia natural. Es él quien termina de desenterrar el esqueleto, no sin problemas (nos situamos en los inicios de la paleontología), ya que se trataba de un trabajo de exhumación muy delicado. Acude al enclave también un dibujante llamado Francisco Javier Pizarro para que «sacara puntual dibujo, antes que se mueva y arriesgue la dislocación o fractura de sus partes, sacando también sus dimensiones en detalle y por el todo» (ver Pimentel 2010, 126-127).

A la postre, los huesos fueron embalados y transportados a Buenos Aires, en donde quedaron almacenados hasta marzo de 1788. Allí, un oficial cartógrafo de origen portugués, José Custodio Sáa y Faria realizó (o copió) dos dibujos que acompañaron al esqueleto en su viaje a España. Uno de los dibujos presenta alguno de los huesos principales del animal por separado, recibiendo cada hueso un tratamiento independiente. El otro dibujo responde a la primera reconstrucción del esqueleto, algo que no se sabe si se llevó a cabo o no efectivamente o si solo se trata de su reconstrucción imaginada en papel.

Aquí radica el gran problema o puzle (nunca mejor dicho), ya que se trataba de ordenar un montón de huesos (piezas) separados y dispersos. La otra cuestión trascendental de este episodio es que no había un modelo, puesto que nuestro animal no guardaba relación con ninguno de los conocidos. Como afirma Pimentel: «La copia a la que se refería Sáa y Faria no podía ser otra cosa que un trabajo innovador, más productivo que reproductivo, más poético que mimético. [...] Para ver aquél animal lo primero que había que hacer era imaginarlo, esto es dotarlo de una imagen» (Pimentel 2010, 130).

He aquí el hecho sorprendente e inesperado dentro de un marco cotidiano: ¿Qué clase de animal podría surgir de esos huesos? El dar respuesta a esta pregunta fue un trabajo ab- 
ductivo de primera magnitud ya que tuvieron que pasar varios años para llegar a una respuesta «satisfactoria, [...] sorprendente y revolucionaria» (Pimentel 2010, 130).

Dos atributos anatómicos parecían perturbar cualquier interpretación: no tenía pezuñas sino garras de carnívoro, pero no se había visto un carnívoro de 5 metros de largo y 2 de ancho. Por otro lado, sus mandíbulas eran de aspecto molariforme, por lo que no podía tratarse de un felino. Aquella extraña quimera (como lo describe Pimentel) parecía un herbívoro por sus piezas dentales y bestia fiera a causa de sus garras. Tampoco era descartable que se tratase de dos individuos de especies diferentes. Una de las teorías en boga del momento era aquella que sostenía que el ser humano, especialmente en América, tenía unos antepasados gigantes ya extintos. No obstante, estas hipótesis quedaban descartadas al extraer el esqueleto de la barranca del río Luján. Seguía, pues, el inefable misterio en pie.

Hay que aclarar que la concepción de la extinción no era, ni mucho menos, el paradigma de la historia natural del siglo XVIII. Solo una minoría albergaba la posibilidad de la existencia de especies diferentes en el pasado. Es decir, los restos encontrados podían pertenecer a un animal no extinto. De hecho, el virrey del Río de la Plata reunió a representantes de las comunidades indígenas para interrogarles con el objetivo de saber si reconocían al animal.

Un nuevo personaje asoma a la palestra de la historia en este itinerario abreviado del descubrimiento del megaterio. Se trata de Juan Bautista Bru de Ramón, pintor y disecador del Real Gabinete de Madrid donde llegó el esqueleto de Luján, autor del montaje y la primera descripción del esqueleto. En el museo madrileño se dedica a pintar, montar y disecar animales, pero dista mucho de ser un naturalista profesional. Según el propio Pimentel, $\ll$ no era la persona indicada para acometer un trabajo de estas características. Sus conocimientos zoológicos no eran reseñables, no digamos ya sobre paleontología de vertebrados» (Pimentel 2010, 146). En todo caso, el asunto era nuevo e inaudito y según insiste el autor del relato, «quizás el caso le venía grande a (casi) todos los naturalistas, anatomistas, expertos en zoología y recolectores de fósiles de la época» (Pimentel 2010, 146).

Hay que destacar las tres tareas que realizó Bru: el montaje, la descripción y los dibujos:

1. El montaje. Se trata de la parte más imaginativa y que requería de muchos conocimientos para llegar a la reconstrucción adecuada. La reconstrucción está plagada de errores osados: «se compró una calavera de una mula para por ella tomar una idea para el arreglo de la del esqueleto y juntamente se compró la cola» (ver Pimentel 2010, 147). A falta de un modelo o patrón, Juan Bautista Bru recurrió a la mula. Para ello tuvo que cortar, serrar y limar muchos huesos, rellenar con corcho muchos otros y añadir otros para encajar en su lecho de Procusto a esta, su criatura inimaginable. Alteraría, así, gravemente la anatomía del vertebrado disponiéndolo en una posición inadecuada que es en la que hoy lo podemos encontrar en el Museo de Ciencias Naturales; es decir, como si de una mula colosal se tratase. De esta configuración destacan dos cualidades que fueron las que cautivaron la atención de los expertos: su enorme tamaño y su extravagante morfología.

2. La descripción. En su descripción, realizada en colaboración con Joseph Garriga, en contra de lo que parecía proponer el montaje, se decanta por una hipótesis más efectista: estamos ante una fiera carnívora y depredadora que «abrigaba en sí toda la ira de los elefantes, toda la furia de los leones y toda la rabia de los tigres» (ver Pi- 
mentel 2010, 151). El esqueleto parecía reunir las características de lo sublime por su grandiosidad terrorífica y su belleza totalmente novedosa.

3. Los dibujos: Los dibujos y grabados fueron realizados por Juan Bautista Bru y Manuel Navarro. El grabado permitía distribuir imágenes idénticas entre los miembros de la comunidad científica para su discusión. Estos grabados permitían el acceso a los restos fósiles de la criatura ignota. Las planchas eran un prodigio de técnica y belleza, según Pimentel. Se grabaron cinco planchas, cuatro de ellas reproducían los huesos aislados y agrupados por criterios anatómicos y la quinta reproduce el esqueleto montado, esto es, la primera reconstrucción de un animal extinto en toda la historia.

Como explica Pimentel, este extraño y magnífico ser carecía de narrativa. Se trataba de una «monstruosidad indecible» (Pimentel 2010, 157), una enorme incógnita, un misterio sin parangón que reclamaba una interpretación convincente. $Y$ es en este momento donde surge el Sherlock Holmes de esta historia. Su nombre es George Cuvier, el gran naturalista, que tuvo acceso al esqueleto gracias a unas copias de los grabados originales: como destaca Pimentel, la ciencia es una actividad social. Estas copias fueron las que dieron pie a un informe, por parte de Cuvier que constituyó, a la sazón, su primer artículo de fósiles y anatomía comparada en 1796 [el mismo año en que se publicó la descripción del esqueleto de Garriga].

Cuvier resolvió el misterio, el enigma de la aparente incoherencia entre la dentición y las garras, empleando sus conocimientos sobre otros vertebrados, en donde jugarán un papel predominante la analogía y la extrapolación. Se basó, primeramente, en lo que se llama morfología funcional, es decir, los órganos de un ser vivo están relacionados entre sí y dependen de las funciones que desempeñan.

Las dos conclusiones que sacó a partir de la copia de los grabados fueron: (1) que aquellos huesos no se correspondían con los de ningún ser vivo conocido y (2) parecían encajar con los edentados, una familia de animales que combinaba esa dentición con esas poderosas garras (extrañamente no unguladas). Se trataba de la familia que incluye a los perezosos, los armadillos y los osos hormigueros. Otras características que encajaban con la hipótesis de la pertenencia con la familia de los edentados eran: (a) la presencia de clavículas, (b) la anchura de las caras de la mandíbula inferior y (c) la gran apófisis en la base del arco cigomático.

Estas especies tropicales eran relativamente desconocidas en Europa y, además, estaba el problema de que su tamaño era mucho menor al de nuestra criatura, por lo que el esqueleto pertenecía a un animal extinto. Esto era otro escollo para sustentar la hipótesis, dado que había que postular un mundo antiguo distinto del actual. Lo bautizaron primeramente como Megatherium Americanum (el gran animal americano), para modificarlo poco después por Meghaterium fossile ya que con esta nomenclatura binomial se apuntaba a ese pasado remoto de una forma extinta. Juan Pimentel nos lo narra mucho mejor de lo que yo pudiera hacerlo: «[E]l joven Cuvier descubrió el misterio de su identidad y lo bautizó con un golpe de ¿cómo llamarlo? ¿Lucidez? ¿Maestría? ¿Ingenio? ¿Método? ¿Rigor científico? ¿Imaginación?» (Pimentel 2010, 180). Y más adelante continúa:

Precisamente Linneo, el nuevo Adán que había rebautizado a los seres vivos, cuando dio con la fórmula binaria de su nomenclatura - un método ideado prácticamente como un juego, con fines mnemotécnicos- dijo tener sensación de haberle colocado el badajo a una campanilla. Así ocurre cuando se encuentra la palabra precisa para designar o nombrar un objeto o un hecho. Algo resuena en su interior. Cuvier lo debió sentir. (Pimentel 2010, 187) 
El badajo del insight, según lo entendía Peirce, nos alerta ante una posible y más plausible reorganización de las piezas.

El Megaterio, como reto científico, enigma atávico y encrucijada del conocimiento, fue objeto de diferentes abordajes interpretativos que fueron otorgándole una morfología cada vez más precisa y coherente. El debate global, gracias a la difusión de los grabados, produjo un diálogo a varias voces genuinamente enriquecedor.

Una de estas voces fue la de Thomas Jefferson, futuro presidente de los EE.UU. y avezado en varias disciplinas entre las que se incluía la paleontología. Jefferson estaba muy interesado por los descubrimientos de un lugar llamado Big Bone Lick, unas marismas al sur del río Ohio. Desde los primeros hallazgos en 1739, donde se habían encontrado huesos de un extraño animal parecido al mamut, hasta la década de 1760 , en la que se habían multiplicado las excavaciones, se erigía otro gran enigma conectado con el megaterio. Al animal de Ohio se le denominó como American incognitum. Dos bandos se enfrentaban en torno al problema de estos huesos, una vez más, misteriosos. Por un lado, aquellos que como el conde Buffon apoyaban la tesis de la inferioridad de la naturaleza americana. Por otro, el bando impugnado, en el que se situaba el propio Jefferson y que sostenía que el centro de América estaba bendecido por las mejores frutas, tierra de promisión fértil y poderosa. Para Buffon, pues, el American incognitum era un animal procedente de una América septentrional con un clima mucho más cálido. Para los del bando jeffersionano (permítaseme la licencia) dentro de su visión providencialista y deísta no había lugar para la extinción de las especies. Dentro de este panorama, en 1797, en Virginia, aparecen los restos de otro curioso animal. Este animal, a diferencia del de Ohio (un mastodonte), en lugar de pezuñas, tenía garras. Jefferson lo bautizó como Megalonyx (gran garra). Tentado a introducir el Megatherium en esta fauna terrible y poderosa, Jefferson lee el artículo de Cuvier y se da cuenta de la similitud entre el gigante perezoso del río Luján y los restos de Virginia: se trataba de una especie gigantesca, en efecto, pero intermedia entre el perezoso y el armadillo. Jefferson tuvo que abandonar la idea de mostrar como prueba de la fiereza de la fauna americana estos restos, asumiendo que la especie de Virginia era más bien similar a uno de los animales que le «servía» a Buffon para defenestrar a la naturaleza americana: el perezoso.

A finales del siglo XVIII parecían generarse dos consensos dentro de la historia natural: la Tierra parecía tener un pasado mucho más largo de lo que se creía y los fósiles eran útiles para aclarar ese pasado.

Cuando se produce esta incógnita o ardiente debate en torno al megaterio, la cuestión sobre el pasado de la Tierra era fundamental para resolver el misterio. Había dos teorías contrapuestas: (1) el modelo uniformista y gradualista de Hutton que abogaba porque los cambios se habían producido por una acción constante de la erosión, la sedimentación y el calor durante millones de años. Y, enfrentado, (2) el modelo catastrofista de Deluc en el que épocas de crisis seguían a otras de gran estabilidad, lo que, en consecuencia, producían dos mundos completamente distintos por la violenta irrupción de una catástrofe. Muchos fósiles, como el nuestro, parecían mostrar una forma muy diferente a la actual, lo que parecía apoyar la tesis de la catástrofe.

La ventaja de Cuvier con respecto a los demás estudiosos de historia natural es que, en París, tenía a su disposición la mayor colección del mundo de vertebrados. La posibilidad de poder tener acceso a un esqueleto de perezoso, «[p] osiblemente el único lugar de Europa donde se podía encontrar» (Pimentel 2010, 244), le permitió a Cuvier relacionarlo con el megaterio. Parecía ser, entonces, que las especies fósiles eran los testigos «mudos» de ese 
mundo perdido. Cuvier, adoptó el modelo binario de Deluc, tesis que resulta equivocada desde nuestros ojos.

No obstante, la cosa no quedó ahí. A partir de 1820, nuevas voces se suman al debate con la publicación de Osteología comparada por parte del embriólogo Heinz Christian Pander y el naturalista Joseph W. Edward D’Alton. Se abre camino una nueva hipótesis que corregía y aumentaba la de Cuvier. Estos hombres, fascinados por el megaterio, en una visita a Madrid, le dedicaron el primer volumen de su tratado. En su obra, consideran que el megaterio y el megalonyx eran los antepasados de los edentados tardígrados, trasladando, así, «la metamorfosis entendida a la manera de Goethe desde las plantas a todos los seres vivos, así individual como colectivamente» (Pimentel 2010, 267). En definitiva, las especies no eran estables, como sostenía Cuvier, sino que se producía una evolución entre las formas vivas. En 1823, Cuvier prepara una nueva edición de su obra y modifica levemente su concepción del edentado. Además, sustituye las imágenes de Bru y Navarro por las de Pander y D’Alton, y, gracias al trabajo de éstos, confirma que Bru estaba equivocado en la disposición de los dedos de las patas delanteras. Tras la muerte de Cuvier, nuevos debates se abrieron en torno a estos flecos sin resolver que pueden acabar con una teoría. La pregunta era qué función tenían ciertos rasgos anatómicos que parecían no tener una explicación. William Buckland, el primer catedrático de geología en la Universidad de Oxford, dio con la clave:

El poderoso hocico del megaterio era en realidad una trituradora de raíces, su pequeña trompa, una herramienta para extraerlas, sus manos unas extractoras afiladas y capaces de llegar hasta grandes profundidades. La robustez de las extremidades inferiores, la fortaleza de la cola, se explicaban por razones de estabilidad y funcionalidad. (Pimentel 2010, 277)

Lo que parecía una anatomía desviada, una desviación de la naturaleza, quedaba ahora explicado en un conjunto anatómico nada gratuito.

La configuración definitiva del megaterio fue debida a Richard Owen que dedicó al megaterio una serie de cinco artículos, aclarando su anatomía y hábitos. La gran y monstruosa incógnita surgida de la tierra como si de una criatura atávica e inefable se tratara quedaba así «resuelta» tras 50 años de animado debate entre las cabezas más inteligentes de su tiempo. El propio Darwin, que en su viaje del Beagle a la Patagonia confundió los restos de un megaterio con los de un rinoceronte, así lo reconoció: «Los hábitos de vida de estos animales eran un completo rompecabezas para los naturalistas, hasta que el profesor Owen resolvió el enigma haciendo gala de un ingenio notable» (ver Pimentel 2010, 289).

Rompecabezas e ingenio, dos palabras que nos muestran el camino para que, terminado el relato, comience el análisis abductivo, centrándonos, principalmente en las figuras de Bru y Cuvier.

\section{Análisis}

Lo primero que hay que considerar son las características singulares que hacen de este caso un acontecimiento de primera magnitud para nuestros intereses. En primer lugar, [Dato-1] nos enfrentamos con una serie de huesos desperdigados. Esta cuestión ya despierta en nosotros un deseo de explicar qué es lo que nos dicen estos signos, pendientes de interpretación.

Pero nuestro caso está repleto de circunstancias increíbles que lo hacen ser una singularidad entre lo singular. Otra cuestión que requiere una explicación particular es [Dato-2] la 
enormidad de los huesos. Algo muy extraordinario ya de por sí. A esto hay que sumarle, la dispersión de los mismos. Estos dos factores convierten a la empresa de reconstrucción en un enigma sin parangón ya que [Dato-3] no hay modelo en el que integrarlos. El descubrimiento se aleja, pues, de lo que sería un caso más cotidiano para alguien entendido, como por ejemplo, el descubrimiento de los huesos de un oso hormiguero, muy comunes en la zona. Vemos cómo, en este caso, el «razonar cotidiano» no es suficiente (logica utens ${ }^{4}$ ) y es cuando las personas entendidas, que se interesan por resolver el misterio, han de reclamar la ayuda de la logica docens, esto es, profundizar en el problema con el fin de resolverlo con todas las herramientas disponibles (estudio, imaginación...). El propio Juan Pimentel habla de trabajo innovador, productivo y práctico. Es por esta razón que podemos hablar de diferentes grados de creatividad dentro de la abducción. Anderson ilustra esta cuestión con un ejemplo que me parece revelador a este respecto:

Supongamos que un granjero ve un ovni sobrevolando un maizal. Este granjero toma nota de la arquitectura del vehículo, de su velocidad, tipo de movimiento... Teniendo en cuenta estos datos hipotetiza que era realmente un tipo de helicóptero particular: un ultraligero, por ejemplo. Este tipo de abducción tendría que ver con lo que Peirce llamó inducción de caracteres. Esta forma de abducción no deja de ser creativa, pero no genera una nueva idea. ${ }^{5}$ (Anderson 1987, 18)

En este aspecto es como si se hubieran encontrado, por ejemplo, los huesos de un oso hormiguero, para el cual sí que habría un modelo al que atenerse. Si seguimos con el ejemplo del ovni, nuestro caso sería más parecido a:

Un granjero que no pudiera encontrar un modelo para el helicóptero e hipotetiza un nuevo modelo de helicóptero. Para él estaría claro que se trata de una aeronave cuyas alas giran alrededor de un eje (rotor) y que se trata de una aeronave de despegue vertical. Con un tamaño y movimiento que se asemeja al del helicóptero pero que no satisface ninguno de los tipos conocidos. Por tanto, conjetura que se estaban haciendo pruebas con un nuevo tipo de helicóptero. Esta abducción, genera una nueva idea y, en este sentido, es más creativa que la primera. (Anderson 1987, 18)

El caso del megaterio supone un reto para sus descubridores, porque, como en el segundo caso del helicóptero, no existe un modelo a mano que satisfaga las características de esos huesos [Dato-3]. Además del inaudito tamaño, existe otro problema, una morfología extraña (como si el helicóptero tuviera dos alas y fuera más alargado de lo normal, pareciéndose también a un avión), por un lado [Dato-4] una mandíbula en la que encajaban molares y [Dato-5] unos dedos que finalizaban en unas garras afiladísimas. No se trata ya solo de un puzle [Dato-1, Dato-2 y Dato-3], sino de que las piezas no encajan [Dato-4 y Dato-5].

A partir de estos cuatro escollos (unos huesos desordenados y dispersos [Dato-1], un tamaño descomunal [Dato-2], la falta de modelo [Dato-3] y una indecible morfología

4 Habría que tener en cuenta que las distintas habilidades que una persona domina con su logica utens varían dependiendo de múltiples factores, pero, fundamentalmente, dependiendo de los conocimientos adquiridos: estos se van incorporan paulatinamente a nuestra manera cotidiana de razonamiento. En este punto me refiero a que el problema del megaterio suponía un reto incluso para las personas con experiencia en la interpretación de huesos: en este caso, la logica utens de este tipo de personas no fue suficiente.

5 En las citas cuya referencia sea un texto en inglés, transcribiré mis propias traducciones. 
[Dato-4 y Dato-5]) hay que tratar de resolver el misterio, proponiendo algunas hipótesis coherentes.

Al extraer el esqueleto parece claro que se trata de un solo animal [Hipótesis-1] ya que no hay huesos repetidos y hay coherencia en el tamaño de los mismos. Si existiera un animal como ese en las proximidades del río Luján [Hipótesis-2] el enigma sería fácilmente resuelto (pasaríamos del problema del ovni-2 al problema del ovni-1). Los propios indígenas, como expertos conocedores de la fauna del lugar, rechazaron tal supuesto [Falsación-Hipótesis-2].

Una vez desechada la hipótesis inicial [Hipótesis-2], nuestro siguiente protagonista, Juan Bautista $\mathrm{Bru}^{6}$, debe afrontar un reto donde se van a reclamar unas cualidades extraordinarias para resolver el caso. Bru comete varios errores y un acierto:

- [Bru-Error-1] Se deja llevar por una interpretación fácil y rutinaria al recurrir a sus referentes más cercanos. A falta de patrón, recurre a una mula para tener una idea de cómo arreglar el esqueleto [Bru-Hipótesis-1].

- [Bru-Error-2] No tiene en cuenta los pequeños detalles hasta el punto de trastornar la posición de varios huesos.

- [Bru-Error-3] Estableció una composición sin tener los suficientes conocimientos de anatomía animal; es un claro caso de un ejemplo de teorizar antes de tiempo, distorsionando los hechos (huesos) para ajustarlos a su teoría. No hay, quizás, modo más gráfico de modificar los hechos que serrarlos, limarlos, cortarlos y rellenarlos de corcho, como hizo el propio Bru con los huesos.

- [Bru-Error-4] En definitiva, al ver que su modelización del esqueleto hacía aguas, en lugar de recolectar nuevos datos, observaciones u opiniones, dio por terminado su trabajo colocándolo en un pedestal en el Real Gabinete. Por otro lado, tampoco se hizo cargo de la incongruencia que suponía considerar al animal como una fiera carnívora [Bru-Hipótesis-2] debido a las garras, sin tener en cuenta su dentición. El lecho de Procusto de nuestro primer protagonista no solo dislocaba huesos, sino que imprimía carácter.

- [Bru-Acierto-1] Si algo se hizo bien en este primer capítulo de nuestra historia fue distribuir imágenes precisas de los huesos a través de los grabados. Esta puesta en común de los descubrimientos fue la que, en último término, permitió su resolución posterior debido a la intervención y diálogo de muchos actores: Cuvier, en primer lugar, pero también Jefferson, Pander y D'Alton, Buckland y Owen, entre otros, que generaron un discurso científico en torno al megaterio dando lugar, finalmente, a su imagen definitiva.

- [Bru-Error-5] No obstante, Bru (y su colaborador en la descripción, Joseph Garriga) no parecen hacer mucho caso del artículo de Cuvier que señalaba los errores que se habían cometido. Su actitud, parece alejarse mucho de lo que hemos llamado docta ignorancia o ignorancia generosa, que debería ser consustancial de toda abducción que se precie.

6 En este punto no entraremos en la hipótesis que llevó al montaje sobre el papel que dibujó (o copió según sus propias palabras) Sáa y Faria, principalmente porque no contamos con ninguna explicación de cómo se realizó ese dibujo. También es probable que ese dibujo que acompañó a los huesos en su viaje a Madrid sesgara la posible interpretación por parte de Bru, pero este asunto también será soslayado, centrándonos en los acontecimientos narrados en el relato. 
Fue George Cuvier quien dio las claves para resolver el enigma. En primer lugar, hay que destacar este diálogo en comunidad [Ventaja-1] (ver, por ejemplo, Walton 2004, 86) gracias a las copias de los grabados [Bru-Acierto-1]. Esta globalización del saber es esencial para, en el caso de Cuvier, haber tenido acceso a documentos que mostraban los hechos (huesos) lo más desnudos posibles.

Cuvier hace gala de tres requisitos necesarios, nunca suficientes, para realizar una abducción certera: [Ventaja-2] una gran imaginación que se sostendrá en la analogía y la extrapolación, [Ventaja-3] una lógica inflexible (los órganos dependen de las funciones que desempeñan y están relacionados entre sí) y [Ventaja-4] una observación aguda que le proporcionará la base para llegar al modelo adecuado (los edentados).

Sus dos primeras conclusiones le alejan de las hipótesis de Bru: está claro que los huesos no pertenecen a un ser vivo conocido [Cuvier-Hipótesis-1], por lo tanto, no se puede adelantar un modelo cercano, sino que hay que hacer una labor comparativa amplia entre lo que se conoce [Cuvier-Acierto-1]. Es muy importante tener en cuenta que las colecciones de animales y seres naturales a las que tenía acceso Cuvier en el Instituto de Francia eran incomparablemente las mejores de la época [Ventaja-5]. A esto hay que añadir el talento natural y los amplísimos conocimientos de Cuvier [Ventaja-6].

Se da cuenta enseguida de los errores evidentes cometidos por Bru en el montaje, y además, asume que no se puede pasar por alto la gran paradoja del que luego bautizó como Megaterio [Cuvier-Acierto-2]: la discordancia entre las garras y la dentadura [Dato-4 y Dato-5]. Había que explicar la función que se derivaba de estos peculiares rasgos anatómicos. A partir de estas incongruencias e incógnitas de inicio, Cuvier tratará de dar una explicación argumentada y cabal.

Cuvier nota que hay una semejanza entre los huesos del esqueleto y los de los edentados [Cuvier-Hipótesis-2]. Además, el gran enigma de la dentición y las garras también quedaría resuelto si recurría a esta familia como modelo [Falsación-Bru-Hipótesis-1 y FalsaciónBru-Hipótesis-2]. Otras cuestiones como la presencia de clavículas, la anchura de la mandíbula inferior y la gran apófisis del arco cigomático [Datos-adicionales] eran observaciones que acumulaban evidencia. Tal vez cada dato por sí mismo no era revelador, pero la secuencia completa hacía plausible la teoría de Cuvier.

No obstante, esta hipótesis provisional se enfrentaba con un problema: el tamaño [Dato-2]. El megaterio era mucho mayor que los miembros de su familia provisional. Esto da lugar a una nueva hipótesis que supone el salto definitivo para perfilar a nuestra criatura. Megatherium fossile, es decir, extinto y perteneciente a un mundo diferente del actual [Cuvier-Hipótesis-3]. Es en este momento en el que se produce un gran salto de la imaginación: el momento del insight donde todo puede recolocarse y adquirir una armonía preestablecida.

A diferencia de Bru, que hubo de utilizar serruchos, cola y limas, Cuvier no manipula los huesos ni los hechos sino que adopta la hipótesis más abarcadora y explicativa.

Esta idea era de una extraordinaria novedad, emparentar a un animal extinto con una familia como la de los edentados [Cuvier-Hipótesis-1+2+3]. Esta hipótesis es osada, profunda y muy explicativa. Es un ejemplo perfecto de lo que Peirce consideraba una nueva idea; a partir de una anomalía «reordenamos nuestra recolección de hechos observados; intentamos reajustarlos para verlos desde una perspectiva nueva que haga que la experiencia insospechada no nos parezca extraña» (Peirce, CP 7.36, 1907).

Como decía Henri Poincaré en El valor de la ciencia, es imposible «una ciencia construida únicamente en vista de sus aplicaciones [porque] las verdades solo son fecundas si están encadenadas entre sí» (Poincaré 1946, 93). El problema del megaterio está encadenado 
así a múltiples debates de la ciencia de la época que lo enriquecen y lo hacen feraz, al tiempo que de sumo interés para sus contemporáneos. Por un lado, Jefferson, con una buena dosis de docta ignorancia rechaza una teoría sobre el animal de Virginia (una gran fiera) que, además, podía ayudarle a recuperar el orgullo de sus tierras (en contra de las teorías de Buffon): asume el gran parecido entre el Megalonyx y el Megatherium y, a su vez, la semejanza de ellos con la familia de los edentados [Falsación-Jefferson-Hipótesis]. No olvidemos esta virtud epistémica de reconocer los propios errores a la luz de nuevos descubrimientos como parte esencial de una «buena» abducción. La primera hipótesis de Jefferson fue modificada con la ayuda del diálogo en comunidad y de su docta ignorancia.

Por otro lado, temas centrales para la Historia Natural como la antigüedad de la Tierra estaban inexcusablemente ligados al hallazgo de fósiles. Las dos principales teorías interpretativas en torno a esta cuestión eran, como hemos visto, el modelo uniformista y gradualista de Hutton y el modelo catastrofista de Deluc. Asociado a este último modelo, surgían conexiones problemáticas con el tema de la Providencia: ¿cómo Dios podía realizar enmiendas a su propia obra? (Este telón de fondo era el marco del cual rescatar teorías para poder explicar este críptico descubrimiento). Cuvier optó por el modelo binario de Deluc que parecía compadecerse bien con su teoría sobre el megaterio [Cuvier-Hipótesis-4]. El contexto del debate científico de la época, encadena, enriquece y conecta estos descubrimientos dentro de esta tupida red de teorías e hipótesis que van cincelando un perfil cada vez más claro de la ignota criatura.

Vemos cómo Cuvier en 1823, al preparar una remozada edición de su obra, va modificando su concepción del edentado [Cuvier-Acierto-3] sustituyendo las imágenes de Bru y Navarro por las de Pander y D’Alton que muestran la mala disposición de los dedos de las patas delanteras de los antiguos grabados. Además, Pander y D’Alton apuntan hacia una nueva clave en la consideración del edentado, al proponer la permanente evolución de las especies, a diferencia de Cuvier, que sostenía su estabilidad. Por último, Buckland y Owen atan los cabos sueltos de la red que comenzará a tejerse partiendo del plan trazado por Georges Cuvier.

Observamos el hecho sorprendente del descubrimiento de unos huesos de un animal ciclópeo y de extraña e inexplicable morfología.

Pero si fuera cierto que estamos ante un fósil de un edentado excavador de raíces, cuyos rasgos anatómicos estaban adaptados al entorno de las pampas sudamericanas desde el Plioceno hasta bien entrado el Holoceno (el Megatherium fossile) [Hipótesis Final], entonces, el hecho sorprendente quedaría explicado como algo corriente y coherente.

Por lo tanto, hay razón para sospechar que estamos ante un Megatherium fossile.

\section{Elementos abductivos}

Pongamos ahora un poco de orden en los datos, hipótesis, errores y ventajas que hemos ido puntualizando a lo largo del análisis.

Datos e hipótesis iniciales:

\begin{tabular}{c|l}
\hline $\begin{array}{c}\text { Datos } \\
\text { directos }\end{array}$ & $\begin{array}{l}{[\text { Dato-1 }] \text { Huesos desperdigados. }} \\
\text { [Dato-2] La enormidad de los huesos. }\end{array}$ \\
\hline \multirow{2}{*}{$\begin{array}{c}\text { Datos } \\
\text { indirectos }\end{array}$} & $\begin{array}{l}\text { [Dato-3] No hay modelo en el que integrarlos. } \\
{[\text { Dato-4] Una mandíbula en la que encajaban molares. }} \\
{[\text { Dato-5] Unos dedos que finalizaban en unas garras afiladísimas. }}\end{array}$ \\
\hline
\end{tabular}


En principio, podemos clasificar los datos en estos dos grupos. El primer grupo serían los datos directos del hallazgo donde no se precisa una observación detallada ni conocimientos de anatomía animal para ser observados. Podríamos decir que cualquiera con su logica utens observa los datos directos.

Para observar como un hecho sorprendente el segundo grupo de datos, los datos indirectos, es preciso poseer ciertos conocimientos. Aquí, se podría decir que los observadores que encuentran fuera de lo común el [Dato-3], el [Dato-4] y el [Dato-5] son aquellos que han aplicado cierta dosis de estudio y voluntad para hallar una explicación del caso. Es importante en una investigación saber qué ha de ser observado (en cierta manera, estos observadores han tenido que sobreponerse a la odiosa rutina; punto 1). Esto no significa teorizar antes de tiempo, sino buscar los elementos discordantes: pequeños detalles que pueden dar con la clave del estudio (punto 2).

\begin{tabular}{c|l}
\hline $\begin{array}{c}\text { Hipótesis } \\
\text { iniciales }\end{array}$ & $\begin{array}{l}\text { [Hipótesis-1] Se trata de un solo animal. } \\
\text { [Hipótesis-2] Si existiera un animal como ese en las proximidades del río Luján el } \\
\text { enigma sería fácilmente resuelto. }\end{array}$ \\
\hline
\end{tabular}

Estas hipótesis iniciales son un magnífico ejemplo del principio de economía peirceano. La Hipótesis-1, podríamos decir, es la hipótesis más plausible para continuar con la investigación además de que ninguna de las observaciones puede refutarla: explicando los datos, es la hipótesis más sencilla. Hipotetizar que tenemos solo una cabeza, una columna vertebral, dos extremidades inferiores, etc. de tamaños proporcionalmente coherentes pero que pertenecen a dos animales distintos violaría gravemente el principio de la economía sin avanzar en la explicación de los hechos.

De igual manera, la Hipótesis-2 sería la solución más sencilla del enigma. Puede que «nosotros» no encontremos modelo para estos huesos descomunales, pero los indígenas, como grandes conocedores de su tierra, podrían resolver el enigma si tal animal existiera en la zona. Además, en este caso, verificar la hipótesis es tan sencillo como apelar a la opinión de los expertos. Una vez más la economía peirceana: la principal ventaja es que la investigación pueda avanzar rápidamente, verificando o falsando las teorías que supongan una comprobación más inmediata.

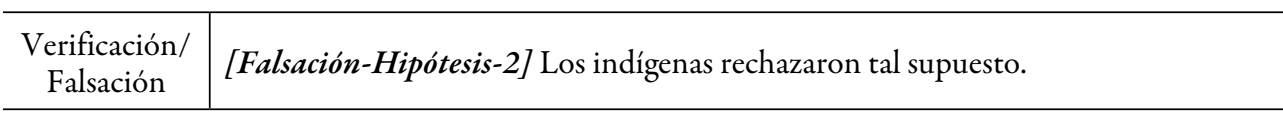

Para verificar o falsar las hipótesis es necesaria la adquisición de nuevos conocimientos: en nuestro caso, bien por encontrar una hipótesis mucho más explicativa (que explique el mayor conjunto de datos) o por encontrar nuevos datos que puedan sostener la hipótesis. Los indígenas actúan como proveedores de nuevas observaciones: no existe animal en los alrededores del río Luján que se corresponda con esa osamenta. Argumentativamente, la falsación de la Hipótesis-2 corresponde con la apelación a fuentes expertas. Habría que preguntarse la capacidad real de estas personas para falsar la hipótesis, pero, en este caso, el argumento revalida el [Dato-3] observado indirectamente por personas con ciertos conocimientos de anatomía animal. Así, se acepta esta hipótesis para seguir avanzando. Huelga decir, que la abducción siempre está sujeta a nuevos datos. 


\section{Montaje de Juan Bautista Bru de Ramón:}

\begin{tabular}{c|l}
\hline $\begin{array}{c}\text { Errores } \\
\text { Bru }\end{array}$ & $\begin{array}{l}\text { [Bru-Error-1] Interpretación fácil y rutinaria al recurrir a sus referentes más cercanos. } \\
\text { (Punto 1) }\end{array}$ \\
& $\begin{array}{l}\text { [Bru-Error-2] No tiene en cuenta los pequeños detalles hasta el punto de trastornar la } \\
\text { posición de varios huesos. (Punto 2) } \\
\text { [Bru-Error-3] Teoriza antes de tiempo, distorsionando los hechos (huesos) para ajus- } \\
\text { tarlos a su teoría. (Punto 3) } \\
\text { [Bru-Error-4] No se preocupa por recolectar nuevos datos. (Punto 3) } \\
\text { [Bru-Error-5] No rectifica su modelo ante hipótesis más plausibles. (Punto 6) }\end{array}$ \\
\hline $\begin{array}{c}\text { Hipótesis } \\
\text { Bru }\end{array}$ & $\begin{array}{c}\text { [Bru-Hipótesis-1] Recurre a una mula como patrón. } \\
\text { [Bru-Hipótesis-2] El animal es una fiera carnívora. }\end{array}$ \\
\hline
\end{tabular}

En este punto, llegamos al momento donde una serie de «errores abductivos» condujeron hacia hipótesis incongruentes que no se hacían cargo de explicar los datos. Gran parte del atractivo de este caso reside en el montaje y la caracterización de Bru. Si nos interesa especialmente el caso del megaterio no es solo porque el hallazgo supuso un cambio de paradigma en las Ciencias de la Naturaleza, ni por el gran salto de la imaginación que tuvo que realizar Cuvier, sino porque tenemos la narración del cómo y el porqué la primera reconstrucción y caracterización resultó fallida. A estas alturas podríamos preguntarnos: si los datos no son explicados, ¿podemos decir que estas hipótesis hayan sido alcanzadas por abducción? Considero que la abducción se produce ante la voluntad de dotar de una explicación con cierto rigor científico a unos hechos. Diremos que nos encontramos ante malas abducciones cuando, como en el caso de Bru, sus hipótesis no dan cuenta de los datos observados. Este análisis pretende hacerse cargo de qué errores llevan a dar con malas abducciones sin entrar en consideraciones de si los protagonistas tenían o no voluntad real de explicar científicamente los hechos.

El catálogo de los errores cometidos por Bru puede contraponerse con aquellos puntos destacados en la introducción. Podríamos apuntar a que Bru no fue capaz de sobreponerse a la odiosa rutina y a los muros mentales de su tiempo para llevar a cabo una buena investigación. También, podemos decir que nuestro protagonista siguió los dictados de su logica utens sin pedir la ayuda de la lógica más refinada: esto es, herramientas conductoras de la logica docens como el estudio o el diálogo razonado fueron sustituidas por serruchos y cola. Lo que queda patente es que Bru no se preguntaba sobre la verdad de sus teorías, o al menos, si era así, los hechos no indican que estas preguntas fueran contestadas satisfactoriamente.

Las dos hipótesis de Bru sobre la osamenta (su analogía con una mula y el carácter carnívoro del «monstruo») son un caso evidente de economía muy mal entendida (elegir las hipótesis que resulten más familiares). En este caso, Bru se basó únicamente en sus referentes más cercanos. Por otro lado, podríamos pensar que Bru no se hizo cargo de los datos indirectos, tal vez por falta de conocimientos. Sin embargo, aunque esto fuera así, no se justifican ni el modelo adoptado para el montaje, ni el hecho de adaptar los huesos para que encajaran, ni que no hubiera rectificación por su parte cuando apareció el artículo de Cuvier.

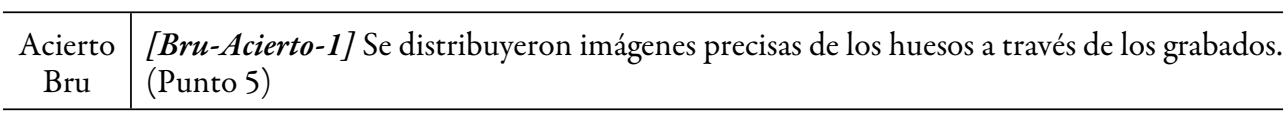


Esta acción supuso la puesta en común del hallazgo. Si bien esta distribución de los grabados supuso el primer paso para dar con la solución del enigma, no hay noticias de que Bru se hiciera eco de las reacciones sobre este descubrimiento del resto de la comunidad científica. Así que, podemos decir, este acierto de Bru supuso un avance para la investigación en sí, no para la investigación del propio Bru. En este sentido, también se podría decir que Cuvier también contaba con la ventaja de los errores cometidos por Bru. Como apuntan Paavola y colaboradores:

Las nuevas ideas se desarrollan a través de una interacción social donde se combinan las ideas previas del investigador y las ideas de otros investigadores. Esto no significa que esta interacción dicte las nuevas ideas, pero dan una dirección hacia ellas. Estas ideas no se desarrollan tan solo de manera lineal (por ejemplo, desde teorías a ideas o desde evidencias a ideas), sino más bien en procesos a largo plazo donde varios hechos relacionados con el objeto de la investigación, varias teorías y perspectivas e ideas sugeridas coexisten como elementos para que el/los investigador/es trabajen con todo ello (Paavola et al., 2006).

Esta interacción social supone un diálogo a varias voces donde existe un intercambio razonado de argumentos en torno un a asunto concreto que guía, activa y termina esclareciendo la propia investigación (punto 5). Considero este diálogo razonado (bien en comunidad, bien entre dos partes, y si se me permite, bien con uno mismo) como una herramienta fundamental que permite argumentar y someter a crítica las hipótesis abductivas.

\section{Investigación de George Cuvier:}

\begin{tabular}{c|l}
\hline $\begin{array}{c}\text { Ventajas } \\
\text { «externas» } \\
\text { Cuvier }\end{array}$ & $\begin{array}{l}\text { [Ventaja-1] Diálogo en comunidad. (Punto 5) } \\
\text { [Ventaja-5] Las colecciones de animales a las que tenía acceso eran las mejores de la } \\
\text { época. }\end{array}$ \\
\hline $\begin{array}{c}\text { Ventajas } \\
\text { Cuvternas» }\end{array}$ & $\begin{array}{l}\text { [Ventaja-2] Imaginación que se sostendrá en la analogía y la extrapolación. (Punto 1) } \\
\text { [Ventaja-3] Lógica inflexible (los órganos dependen de las funciones que desempeñan y } \\
\text { están relacionados entre sí). (Punto 2) } \\
\text { [Ventaja-4] Observación aguda que le proporcionará la base para llegar al modelo ade- } \\
\text { cuado. (Puntos 3 y 4) } \\
\text { [Ventaja-6] Amplísimos conocimientos. }\end{array}$ \\
\hline $\begin{array}{c}\text { Aciertos } \\
\text { Cuvier }\end{array}$ & $\begin{array}{l}\text { [Cuvier-Acierto-1] Hay que hacer una labor comparativa amplia entre lo que se conoce. } \\
\text { (Puntos 3 y) } \\
\text { [Cuvier-Acierto-2] No se puede pasar por alto la discordancia entre las garras y la denta- } \\
\text { dura. (Punto 2) }\end{array}$ \\
\hline $\begin{array}{c}\text { Hipótesis } \\
\text { Cuvier }\end{array}$ & $\begin{array}{l}\text { [Cuvier-Hipótesis-1] Los huesos no pertenecen a un ser vivo conocido. } \\
\text { [Cuvier-Hipótesis-2] La semejanza entre los huesos del esqueleto y los de los edentados. }\end{array}$ \\
\hline $\begin{array}{c}\text { Nuevos datos } \\
\text { explicados }\end{array}$ & $\begin{array}{l}\text { [Datos-adicionales] Clavículas, la anchura de la mandíbula inferior y la gran apófisis del } \\
\text { arco cigomático. }\end{array}$ \\
\hline $\begin{array}{c}\text { Verificación/ } \\
\text { Falsación }\end{array}$ & $\begin{array}{l}\text { [Falsación-Bru-Hipótesis-1] y [Falsación-Bru-Hipótesis-2] } \\
\text { [Falsación-Jefferson-Hipótesis] }\end{array}$ \\
\hline $\begin{array}{c}\text { Hipótesis } \\
\text { Cuvier }\end{array}$ & $\begin{array}{l}\text { [Cuvier-Hipótesis-3]Megatherium fossile, es decir, extinto y perteneciente a un mundo } \\
\text { diferente del actual. } \\
\text { [Cuvier-Hipótesis-4] Adopta el modelo binario de Deluc. }\end{array}$ \\
\hline $\begin{array}{c}\text { Aciertos } \\
\text { Cuvier }\end{array}$ & $\begin{array}{l}\text { [Cuvier-Acierto-3] Edición remozada de su obra donde modifica ligeramente su con- } \\
\text { cepción del edentado. (Punto 6) }\end{array}$ \\
\hline
\end{tabular}


En primer lugar, se ha de señalar que lo que hemos denominado «ventaja» es una combinación de elementos del contexto (ventajas «externas») y las habilidades propias de cada persona (ventajas «internas»). Pero para que puedan ser consideradas como tal, hay que sacar provecho de las mismas. Para ello, hay que reclamar la ayuda de la logica docens, es decir, apelar al razonar crítico en un determinado contexto. No es relevante para la investigación ser una persona muy imaginativa o tener acceso a la mejor colección de vertebrados del mundo si no existe la voluntad, primero, de resolver el enigma. Por otro lado, tener unos conocimientos profundos sobre anatomía animal le hace darse cuenta de la verdadera incógnita que planteaba ese montón de huesos. Para Cuvier el misterio se magnifica hasta su dimensión real: Cuvier es capaz de sentir el verdadero problema que supone no encontrar una solución, dejando ese enorme cabo suelto en la Historia Natural.

Dicho esto, las ventajas que Cuvier supo aprovechar le llevaron a encaminar la investigación en dos direcciones novedosas. Estos son los aciertos de Cuvier: repasar la anatomía de cada especie conocida buscando analogías (punto 1, 3 y 4) y fijar especial atención en la aparente discordancia entre las garras y la dentición (punto 2). Este estudio le llevó a las Hipótesis 1 y 2. Estas dos hipótesis eran compatibles con la Hipótesis incial-1, explicaban los datos $[1,3,4,5]$ además de los otros datos adicionales. Por otro lado, estas hipótesis desmontaban aquellas adoptadas por Bru [Falsación-Bru-Hipótesis-1 y Falsación-Bru-Hipótesis-2] (punto 5) debido a que son mucho más explicativas, reordenando los datos en un todo coherente. Además, estas hipótesis de Cuvier fueron suficientes para alertar a Jefferson sobre lo inadecuado de su teoría sobre el megalonyx [Falsación-Jefferson-Hipótesis] (punto 5 y 6). En este caso, el propio Jefferson, inmerso en este diálogo en comunidad (punto 5), renunció a una teoría que «probaba» la riqueza de la fauna americana (punto 6) en pro de esa «verdad» abductiva propuesta por Cuvier que emergía como un volcán y arrasaba cualquier otra consideración.

En este punto, a pesar de la buena explicación que suponía identificar el esqueleto con un animal no conocido de la familia de los edentados, Cuvier no dio por terminada la investigación (punto 6). El descomunal tamaño de los huesos quedaba sin explicación [Dato-2]. Aquí es donde Juan Pimentel subraya el verdadero salto de la imaginación y nosotros lo identificaremos con el insight, el instante del instinto (Duarte 2015). La Hipótesis 3 de Cuvier supone un verdadero cambio de paradigma en la Historia Natural. Hablar (o pensar), como posibilidad real, en mundos diferentes al actual en cuanto a fauna se refiere suponía una idea totalmente novedosa.

El enigma del megaterio conectaba de manera irremisible con el debate en torno a la historia de la Tierra. La apuesta de Cuvier por el modelo de Deluc [Cuvier-Hipótesis-4] era razonable en base a su hipótesis del megaterio. Sin embargo, Cuvier, inmerso en el diálogo en comunidad (punto 5), sigue ejercitando la docta ignorancia (punto 6) cuando prepara su revisión del megaterio [Cuvier-Acierto-3] en base a los estudios de Pander y D'Alton quienes apoyaban el modelo gradualista de Hutton.

\section{Visión final del megaterio:}

Hipótesis

final
[Hipótesis Final] Estamos ante un fósil de un edentado excavador de raíces cuyos rasgos anatómicos estaban adaptados al entorno de las pampas sudamericanas desde el Plioceno hasta bien entrado el Holoceno (el Megatherium fossile). 
En esta Hipótesis Final sobre el megaterio cobra una especial relevancia este diálogo en comunidad (punto 5). Esta interacción dialógica entre distintas partes de la investigación toma la forma argumentativa. En definitiva, lo esencial es que la abducción busca en todas partes las herramientas que le lleven a explicar los hechos y no se preocupa del tiempo (50 años de debate sobre la criatura no son nada) ni se asusta ante nuevas observaciones o teorías que cambien el rumbo de la investigación. Las «buenas» abducciones nunca dejan de ser falibles y relativas a un contexto dado, y en este sentido, el diálogo y la interacción social se convierten en fundamentales en el desarrollo científico. Paavola et al. (2006) enfatizan este papel social de la abducción: por un lado, señalan un marco dialógico atendiendo a los modelos interrogativos de la investigación y, por otro, amplían esta visión con lo que denominan un marco «trialógico» en el que esta puesta en común de las investigaciones cobra un papel fundamental.

\section{Conclusión}

En este artículo hemos analizado la generación de hipótesis en un caso real de la historia de la ciencia: el megaterio. La narración de este descubrimiento por parte de Juan Pimentel revela ciertos aspectos que lo dotan de un especial interés desde el punto de vista de la metodología de la abducción: la contraposición entre las hipótesis adoptadas por parte de Bru en el montaje y aquellas enunciadas por Cuvier en su investigación sobre el mismo objeto nos ha llevado a indagar sobre la metodología que dio lugar a unas y otras.

Este estudio nos lleva a defender que las nuevas ideas, en este caso revolucionarias, surgen a través de todo un proceso abductivo (tanto generación como evaluación de hipótesis) donde se entremezcla la imaginación, los conocimientos y la pericia personal con una cierta metodología conectada con el rigor científico, los procesos argumentativos (diálogo razonado) y la capacidad de autocrítica (docta ignorancia). Veamos cómo una vez culminado este proceso abductivo, los puntos estudiados según el plan indicado desde el principio ponen de manifiesto ciertas características esenciales de la abducción:

1. Rutina: los procesos abductivos se activan ante hechos sorprendentes (detonadores abductivos, ver Aliseda 2006). No salirse de la rutina implica un reajuste forzado de este carácter sorprendente (véase el recurso de la mula por parte de Bru).

2. Pequeños detalles: la abducción es la inferencia explicativa que trata de reordenar los datos recogidos en una investigación. En este caso, observar (como hizo Cuvier) en vez de ignorar la discordancia entre la dentición y las garras supuso el punto clave para generar hipótesis abarcadoras.

3. Precipitación: nuestros hábitos se ven quebrados por un fenómeno sorprendente. Esto produce una irritación que demanda una regularización del fenómeno a través de la abducción (ver Nubiola 2005, 124-125). Precipitarnos con hipótesis que no se hacen cargo de los datos es tratar de volver forzadamente al hábito y a la rutina. Bru, al recurrir a sus referentes más cercanos para el montaje, trata de forzar la conclusión de la investigación.

4. Alternativas: las hipótesis abductivas han de ser lo más amplias posibles con el fin de no inclinar la balanza hacia una determinada solución sin poseer las evidencias necesarias para hacerlo. En este sentido, generar un conjunto reticular de hipótesis 
alternativas es una buena estrategia para no sesgar la investigación. En este caso, las hipótesis iniciales en torno a los huesos y la labor comparativa de Cuvier ejemplifican esta buena práctica de buscar siempre hipótesis alternativas.

5. Diálogo razonado: la abducción lleva asociada tanto la generación como la selección y evaluación de las hipótesis. Hacer uso de las buenas prácticas argumentativas es la mejor manera de someter a crítica las hipótesis abductivas. Además, estas prácticas son esenciales para que la abducción presente una dimensión social. Hemos visto cómo el diálogo en comunidad fue fundamental para llegar a la visión final del megaterio.

6. Ignorancia generosa: las hipótesis abductivas siempre son revisables y están sujetas a nuevas evidencias. La virtud epistémica de la docta ignorancia es fundamental para entender y poner en práctica los beneficios que surgen de este carácter falible de la abducción. Quizás, el mayor error de Bru fue no hacer uso de esta virtud ante las críticas bien argumentadas de Cuvier.

En definitiva, las «buenas» abducciones, adquieren su bondad por el hecho de estar enunciadas críticamente (no por su acierto) y, por tanto, siempre podrá seguirse la reconstrucción del proceso abductivo que desvele los elementos metodológicos involucrados.

\section{REFERENCIAS}

Aliseda, Atocha. 2006. Abductive Reasoning. Logical Investigations into Discovery and Explanation. Dordrecht: Springer.

Anderson, Douglas R. 1987. Creativity and the philosophy of C.S. Peirce. Dordrecht; Boston; Lancaster: Martinus Nijhoff Publishers.

-. 2005. The esthetic attitude of abduction. Semiotica 153(1): 9-22.

Chiasson, Phyllis. 2001. Logica Utens. Last modified January 2001. Accessed June 2, 2016. http://www. digitalpeirce.fee.unicamp.br/p-logchi.htm.

Debrock, Guy. 1998. El ingenioso enigma de la abducción. Analogía Filosófica XII/1: 21-40.

Duarte, Antonio. 2015. Abducción y diálogo persuasivo: Elemental, querido Peirce. Revista Iberoamericana de Argumentación 11: 1-33.

Eco, Umberto, y Thomas A. Sebeok, Eds. 1988. The sign of three: Dupin, Holmes, Peirce. Bloomington: Indiana University Press.

Eemeren, Franz H. van, y Rob Grootendorst. 1984. Speech Acts in Communicative Discussions. Dordrecht; Providence: Foris.

Fann, K. T. 1970. Peirce's Theory of Abduction. The Hague: Martinus Nijhoff.

Hintikka, Jaakko. 1998. What is Abduction? The Fundamental Problem of Contemporary Epistemology. Transactions of the Charles S. Peirce Society, 34(3): 503-533.

-. 2007. Socratic Epistemology. Explorations of Knowledge-Seeking by Questioning. Cambridge: Cambridge University Press.

Mayer, Richard E. 1986. Pensamiento, resolución de problemas y cognición. Barcelona: Paidós.

Montaigne, Michel. 1998. Ensayos III. Madrid: Cátedra.

Niño, Douglas. 2007. Abducting Abduction. Avatares sobre la comprensión de la Abducción de Charles S. Peirce. Tesis Doctoral. Universidad Nacional de Colombia.

Nubiola, Jaime. 2005. Abduction or the Logic of Surprise. Semiotica 153(1/4): 117-130.

Paavola, Sami. 2004. Abduction as a Logic and Methodology of Discovery: The importance of strategies. Fundations of Science 9(3): 267-283. 
Paavola, Sami, Kai Hakkarainen, y Matti Sintonen. 2006. Abduction with Dialogical and Trialogical Means. Logic Journal of the IGPL 14(2): 137-150.

Peirce, Charles Sanders. 1931-1958. Collected Papers, vols. 1-8. C. Editado por Charles Hartshorne, Paul Weiss y Arthur W. Burks. Cambridge MA: Harvard University Press. $(C P)$

Pietarinen, Ahti-Veikko. 2005. Cultivating habits of reason: Peirce and the logica utens versus logica docens distinction. History of Philosophy Quarterly 22(4): 357-372.

Pimentel, Juan. 2010. El Rinoceronte y el Megaterio, un ensayo de morfología histórica. Madrid: Adaba editores.

Poincaré, Henri. 1946. El valor de la ciencia. Buenos Aires: Espasa Calpe.

Rivadulla, Andrés. 2015. Abduction in Observational and in Theoretical Sciences. Some Examples of IBE in Palaeontology and in Cosmology. Revista de Filosofia 40(2): 143-152, acceso 9 Junio 2016, http://dx.doi. org/10.5209/rev_RESF.2015.v40.n2.50060

Walton, Douglas N. 1992. Types of Dialogue, Dialectical Shifts and Fallacies. En Argumentation Illuminated, editado por Franz H. van Eemeren, Rob Grootendorst, J. Anthony Blair y Charles A.Willard, 133147. Amsterdam: SICSAT.

-. 2004. Abductive Reasoning. Tuscaloosa, AL: The University of Alabama Press.

Antonio Duarte Calvo es doctor en Filosofía por la Universidad Complutense de Madrid (UCM) y licenciado en Filosofía (Universidad Autónoma de Madrid), en Ciencias de la Información (UCM) y en Antropología Social y Cultural (UCM). Desde febrero del 2014 es profesor asociado en el Dpto. de Lógica y Filosofía de la Ciencia de la Facultad de Filosofía de la Universidad Complutense de Madrid. En este departamento lleva desempeñando labores docentes desde el año 2011.

Dirección: Dpto. de Lógica y Filosofía de la Ciencia, Facultad de Filosofía, Edificio B, Universidad Complutense de Madrid, 28040 Madrid. E-mail: antduart@ucm.es 